
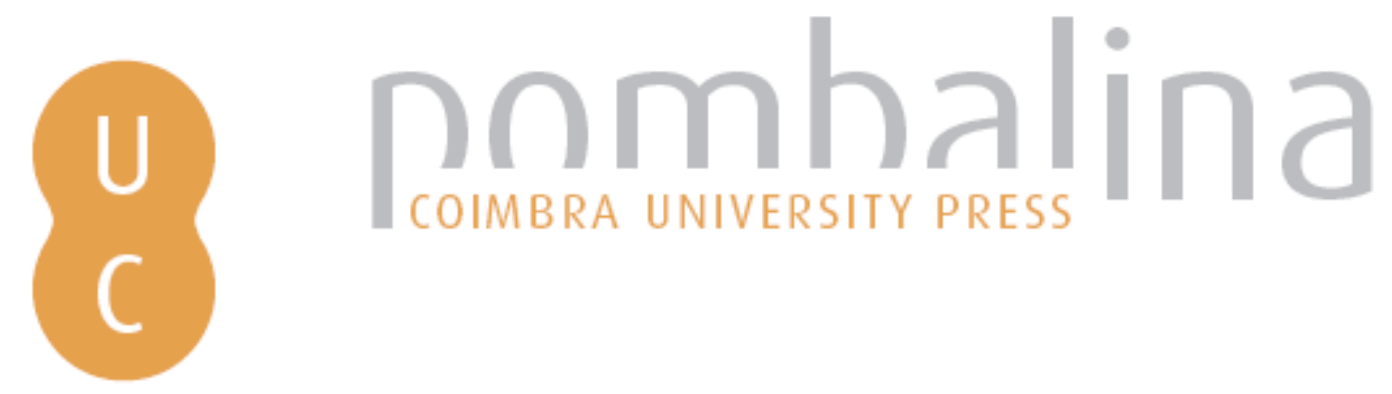

\title{
Levantamento da concepção de risco ambiental e áreas de risco na escola básica em São João del Rei - Brasil: resultado preliminar
}

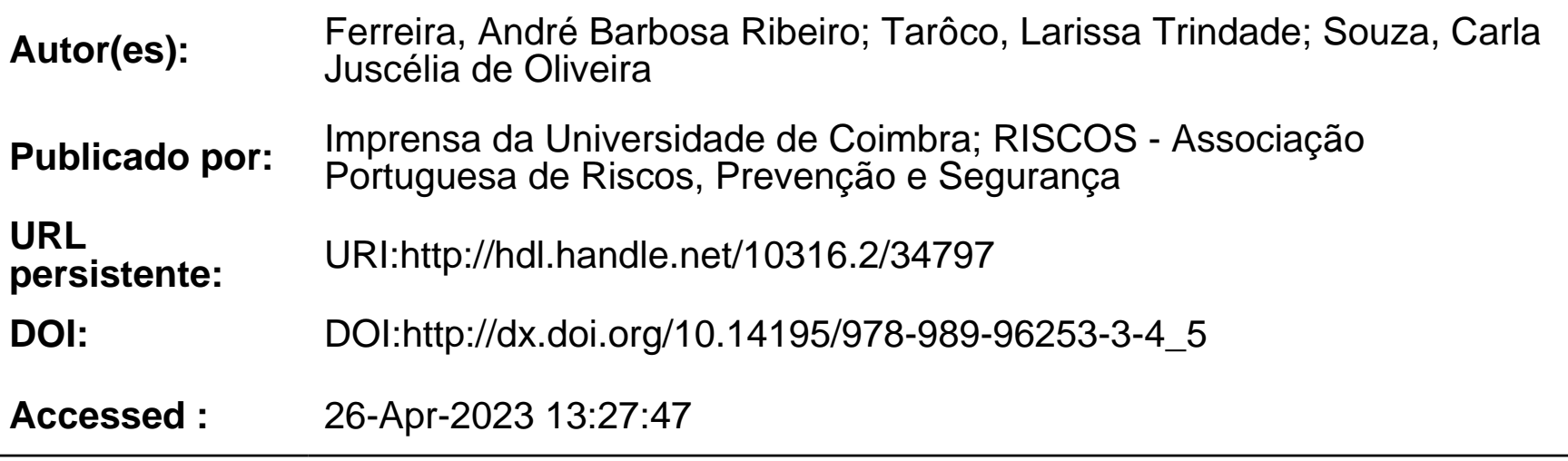

A navegação consulta e descarregamento dos títulos inseridos nas Bibliotecas Digitais UC Digitalis, UC Pombalina e UC Impactum, pressupõem a aceitação plena e sem reservas dos Termos e Condições de Uso destas Bibliotecas Digitais, disponíveis em https://digitalis.uc.pt/pt-pt/termos.

Conforme exposto nos referidos Termos e Condições de Uso, o descarregamento de títulos de acesso restrito requer uma licença válida de autorização devendo o utilizador aceder ao(s) documento(s) a partir de um endereço de IP da instituição detentora da supramencionada licença.

Ao utilizador é apenas permitido o descarregamento para uso pessoal, pelo que o emprego do(s) título(s) descarregado(s) para outro fim, designadamente comercial, carece de autorização do respetivo autor ou editor da obra.

Na medida em que todas as obras da UC Digitalis se encontram protegidas pelo Código do Direito de Autor e Direitos Conexos e demais legislação aplicável, toda a cópia, parcial ou total, deste documento, nos casos em que é legalmente admitida, deverá conter ou fazer-se acompanhar por este aviso.

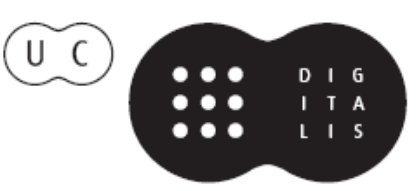



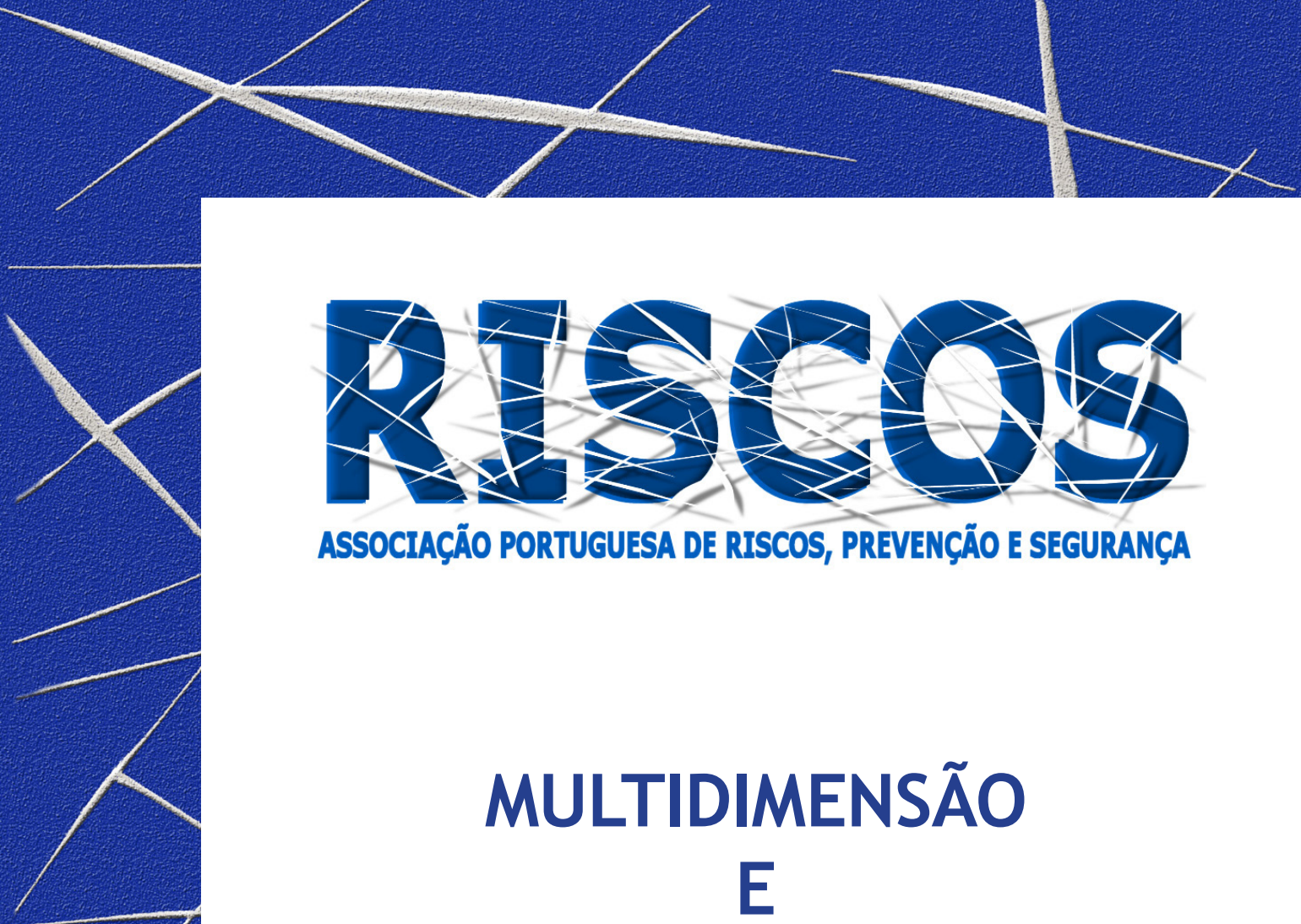

ASSOCIAÇÃO PORTUGUESA DE RISCOS, PREVENCCÃO E SEGURANÇA

MULTIDIMENSÃO

E
TERRITÓRIOS DE RISCO

III Congresso Internacional

I Simpósio Ibero-Americano

VIII Encontro Nacional de Riscos

Guimarães

2014 


\title{
LEVANTAMENTO DA CONCEPÇÃO DE RISCO AMBIENTAL E ÁREAS DE RISCO NA ESCOĹA BÁSICA EM SÃO JOÃO DEL REI - BRASIL: RESULTADO PRELIMINAR
}

\author{
André Barbosa Ribeiro Ferreira \\ Departamento de Geografia, Universidade Federal de São João del Rei/MG, Brasil \\ andreribeirogeo@gmail.com \\ Larissa Trindade Tarôco \\ Departamento de Geografia, Universidade Federal de São João del Rei/MG, Brasil \\ larissa_taroco1994@hotmail.com \\ Carla Juscélia de Oliveira Souza \\ Departamento de Geociências, Curso de Geografia \\ Universidade Federal de São João del-Rei/MG, Brasil \\ carlaju@ufsj.edu.br
}

\begin{abstract}
RESUMO
Os desastres ambientais ocorrem em todo mundo com frequência, devido à combinação de fatores naturais e à intensificação e ação antrópica. Diante disso, surgiu o interesse por investigar a maneira como o tema é discutido na disciplina de Geografia, em duas escolas públicas de São João del-Rei, por meio de um projeto piloto, no âmbito de pesquisa de iniciação científica em andamento. Esse objetivou efetuar diagnóstico sobre o conhecimento e a concepção de risco ambiental e área de risco presentes entre alunos, além de investigar como o assunto é trabalhado pelos professores de Geografia. O levantamento e diagnóstico serão feitos através da coleta de informações por meio de questionário semiestruturado e, também pela observação em sala de aula durante a discussão do assunto. As bases teóricas que fundamentam a pesquisa encontram-se no contexto da Geografia e da Psicologia, referentes à noção de representação, percepção e de "Riscos". A fase atual do trabalho compreende leituras, contato com os sujeitos das escolas e início da coleta de dados nas escolas. Durante a coleta, ainda sem a análise das respostas escritas, foi possível constatar entre as falas dos alunos a ideia de que em situação de inundações das casas o que tem há fazer é esperar a água abaixar, como acontece sempre quando há inundações na cidade. Os resultados finais estão previstos para novembro de 2014. A partir deles, espera-se propor atividades e ações com intuito de alertar, orientar e educar a população escolar para os riscos ambientais.
\end{abstract}

Palavras-Chave: Concepção; Risco Ambiental; Educação Geográfica.

\section{Introdução}

Atualmente destaca-se uma grande preocupação com os riscos ambientais. Estes, conforme Zanirato et. al. (2008), até a década de 1980 eram objeto de estudo unicamente da geografia física, enquanto as atividades de riscos sociais eram objeto da geografia humana, até que movimentos franceses geraram a unificação da problemática dos riscos, alegando que os mesmos possuem envolvem características humanas e físicas, sendo socialmente construído e psicologicamente orientado. Os riscos não constituem em si um novo campo de estudo ou disciplina especificamente geográfica e sim um tema de abordagem global que integra ciências como a geologia, meteorologia, química, física, sociologia e outras (VEYRET, 2007). No entanto, a geografia, por ser uma área de estudo ampla, multidisciplinar, físico e social, ocupa um lugar evidente nesse meio da problemática do risco, ela se interessa pela percepção, gestão e dimensão espacial dos riscos. A percepção do risco ocorre na escala do indivíduo e deve ser considerada no coletivo da população, para fins de conhecimentos que possam contribuir para a formação dessa população ou da comunidade, inclusive a escolar. A escola, como instituição socialmente reconhecida como espaço e tempo para a educação formal, deve contribuir para 
com essa percepção, consciência e leitura do mundo, a partir de problematizações sobre situações cotidianas (SOUZA, 2013). A educação é uma forma de intervenção no mundo e o educando precisa se conscientizar de que ele é um agente transformador do mundo, capaz de refletir criticamente sobre seu papel nos processos sociais, transcendendo para a ideia de que ele pode promover profundas transformações em si e no mundo em que vive.

No Brasil existem os Parâmetros Curriculares Nacionais (PCN's), documento auxiliar nas orientações de temas e conteúdos por área de conhecimento, como Meio Ambiente. Neste e nos conteúdos de Geografia existe a indicação para se trabalhar com o tema riscos ambientais. A escola e a Geografia escolar tem abordado esse conteúdo? Ao término do Ensino Fundamental Il e Ensino Médio, qual a concepção e percepção que os alunos apresentam sobre esse risco ambiental? Essas questões, combinadas com a importância do assunto e a possibilidade de contribuição da escola e da Geografia, motivaram a realização da pesquisa sobre concepção de riscos ambientais, entre alunos e professores do $9^{\circ}$ ano do Ensino Fundamental da Escola Municipal Pio XII e do $3^{\circ}$ ano do Ensino Médio da Escola Estadual Milton Campos, como projeto piloto. Um dos objetivos é verificar se a concepção de área de risco ambiental, entre os jovens, se encaixa nas perspectivas “da Submissão, do Combate ou da Interação e Entendimento", como discutidas por Nunes (2009). A seleção dessas escolas deve-se ao fato de que o bairro está localizado, em sua maior parte, em áreas consideradas como de risco, estando susceptíveis a alagamentos, inundações e desmoronamentos. São João del-Rei possui 88.469 habitantes, sendo 79.857 residentes em área urbana. Desse total, 20.153 habitantes residem no bairro Matozinhos (IBGE, 2010), o qual é o maior bairro da cidade. O referido bairro apresenta topografia predominantemente plana, cortada por vários canais fluviais, como o córrego da Água limpa, Córrego do Lenheiro e o Rio das Mortes. Segundo Passarelli (2012), no ano de 1917 já havia relatos jornalísticos sobre a "pavorosa enchente de segunda feira", que causou enormes estragos no local, arrastando pontes e casas. A última grande enchente ocorreu no ano de 2012 e deixou cerca de 800 residências alagadas e 300 famílias desalojadas.

\section{Procedimento metodológico}

Com base nos pressupostos teóricos e conceituais citados neste texto, a pesquisa está sendo realizada em três etapas inter-relacionadas: leituras e pesquisas sobre a área de estudo, trabalho de campo e gabinete. Para as etapas têm-se os procedimentos técnico-operacionais como: i) revisão bibliográfica, para o entendimento de representação, conhecimento e definição de espaço e lugar, com objetivo de se entender as inter-relações existentes entre esses e o homem; ii) trabalhos de campo, para localização das áreas de risco no bairro Matozinhos; levantamento do número de alunos matriculados no $9^{\circ}$ ano do Fundamental II e no $3^{\circ}$ ano do Ensino Médio, registros fotográficos e pesquisa na Defesa Civil e Prefeitura Municipal; iii) elaboração do questionário semiestruturado; iv) coleta de dados primários entre os sujeitos da pesquisa v) tabulação, sistematização, representação gráfica, análise e interpretação dos dados.

\section{Breve revisão sobre o tema}

De acordo com Kuhnen (2009) a percepção dos riscos ambientais atrela-se a estudos da psicologia social e psicologia ambiental, levando em conta que a situação perigosa se converte em desastre devido ao comportamento dos sujeitos e sua compreensão do lugar, da sua experiência não nítida, do seu apego ao território e apropriação do espaço sem efetuar a pausa para o 
conhecimento. Tal pausa faz do espaço desconhecido um lugar (TUAN, 1983), mas a ausência da percepção leva o indivíduo a se instalar e reinstalar em zonas de risco. Nesse sentido surge à influência do trabalho exercido pela psicologia social e ambiental, intervindo em uma sociedade que não avalia os riscos. A percepção de risco não é um mero estímulo físico objetivo, ele é uma construção social subjetiva e multidimensional já que se trata de juízos, atribuições, memória, emoção, motivação, categorização sobre o risco ou as distintas fontes de risco tecnológicas, ambientais ou sociais.

Risco, segundo Zanirato (2008), é qualquer coisa que possua um potencial de transformação prejudicial para os indivíduos que ocupam determinado espaço. O risco passa a existir quando as transformações ocorrem em ritmo acelerado, ultrapassando o potencial de tolerância do meio e iniciando uma situação que conduz a catástrofes. Ele representa a percepção de um possível perigo previsível pela experiência própria ou indireta de determinado indivíduo ou grupo social (ZANIRATO, 2008). Para Dagnino (2007), o risco se apresenta em situações ou áreas em que existe a probabilidade, susceptibilidade, vulnerabilidade, acaso ou azar de ocorrer algum tipo de ameaça, perigo, problema, impacto ou desastre. De acordo com Veyret (2007), o risco pode ser definido como um conhecimento e uma percepção da ameaça comum a um determinado grupo social. O risco surge a partir do momento em que um grupo integra perigo e sua estimativa depende da maneira de integração e percepção da sociedade em relação à ocorrência de uma crise ou catástrofe. Sendo assim o risco é inscrito em dado contexto social, econômico e cultural, apresentando uma grande dose de subjetividade que se traduz em diferentes limites de aceitabilidade. Segundo Moraes (1998), os riscos ambientais integram um dos complexos aspectos de interação entre homem e natureza e decorrem da estreita interação do homem com o meio. Portanto os riscos não são naturais por si só, eles resultam da interação da natureza, sociedade e indivíduo.

Segundo Veyret (2007), os riscos naturais são pressentidos, percebidos e suportados por um grupo social ou um indivíduo sujeito a ação possível de um processo físico, enquanto o risco ambiental é uma associação deste com os processos agravados pela atividade humana e pela ocupação do território. A expansão da ocupação humana, seguida de instalações materiais tem aumentado continuamente os espaços ou áreas de riscos. Essas áreas são consideradas como são impróprias para o assentamento humano devido a sua instabilidade e fragilidade, são susceptíveis a ocorrência de fenômenos naturais ou induzidos que geram consequências sociais, econômicas e ambientais (SALES, 2010).

\section{Resultados parciais}

Até setembro de 2014 foram realizadas leituras para a fundamentação teórica, trabalhos de campo e visita às escolas. Os trabalhos de campo foram divididos em duas partes. Durante a primeira, as áreas, susceptíveis a alagamentos, foram identificadas por meio de visita in loco, nas proximidades do Rio das Mortes e do Córrego Água Limpa. Na segunda, as áreas de risco de deslizamentos foram levantadas e registradas por meio de fotografias. As leituras, as imagens e registros coletados em campo (Foto 1 e Foto 2) colaboraram para entendimento do sistema local e contribuíram para elaboração dos questionários e entrevistas. Os questionários apresentam questões referentes ao conhecimento que os discentes possuem sobre área de risco e como o assunto é retratado pelo professor de Geografia. Os questionários aplicados aos professores avaliarão suas práticas de ensino referentes ao tema e confirmarão ou não, através de comparações, a compatibilidade de respostas entre discentes e docentes. 

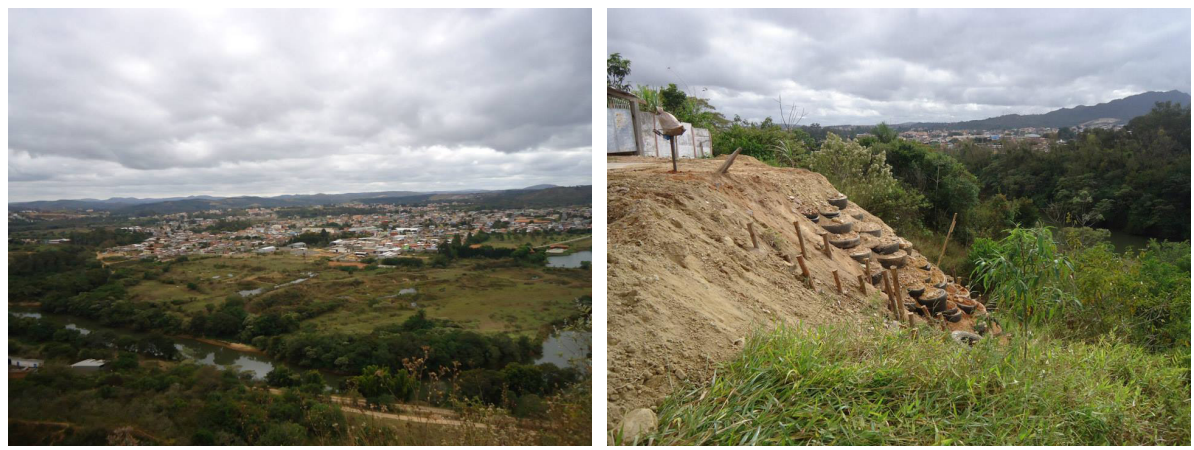

Fotos 1 e 2: Vista parcial da várzea do Rio das Mortes; Lote em aterro e contenção. Fonte: Acervo dos autores, 2014.

O número de alunos do $9^{\circ}$ ano corresponde a 52 ( 2 turmas) e do $3^{\circ}$ ano do Ensino Médio à 105 (3 turmas). Desse total, $94 \%$ responderam o questionário, o qual ainda não foi analisado, em função do prazo extinto para envio do presente texto ao congresso. Apesar disso, durante a coleta, ainda sem a análise das respostas escritas, foi possível constatar entre as falas dos alunos a ideia de que em situação de inundações das casas o que se tem a fazer é esperar a água abaixar, como acontece sempre que ocorrem inundações na cidade.

\section{Conclusão}

$\mathrm{Na}$ região do bairro Matozinhos existem vários trechos susceptíveis a inundações e deslizamentos, durante a estação chuvosa em São João del-Rei. Nesses trechos existe ocupação por residência, galpões e pastagens. Os alunos das duas escolas residem próximos a esses trechos e, portanto, conhecem "de perto" a alteração da paisagem durante as cheias dos rios. Os resultados finais estão previstos para novembro de 2014. A partir deles, espera-se propor atividades e ações com intuito de alertar, orientar e educar a população escolar para os riscos ambientais.

\section{Bibliografia}

DAGNINO, R; JUNIOR, S (2007). Risco Ambiental: Conceitos e Aplicações. Climatologia e Estudos da Paisagem Rio Claro - Vol.2 - n.2, p. 50.

IBGE (2014) - Instituto Brasileiro de Geografia e Estatísticas. IBGE Cidades - São João del-Rei. Disponível em: <http: / / www.cidades.ibge.gov.br/xtras/perfil.php?lang=\&codmun=316250\&search=minasgerais | sao-joao-del-rei>.

KUHNEN, A (2009). Meio Ambiente e vulnerabilidade - a percepção ambiental de risco e o comportamento humano. Geografia (Londrina) v. 18, n. 2, 2009 http://www.uel.br/revistas/uel/index.php/ geografia.

NUNES, Lucí Hildago (2009). Compreensões e ações frente aos padrões espaciais e temporais de riscos e desastres. Territorium, v. 16, p. 181-189.

MORAES, D (1998). A percepção do Meio Ambiente: Contribuições ao estudo dos Riscos Ambientais. Revista Humanitas, v.2, n². Campinas.

PASSARELLI, U (s.d); Matosinhos, Histórias e Festas - Pontes de Matosinhos. 2012.Disponível em: < http:// festadodivinosjdr.blogspot.com.br/2012/12/pontes-de-matosinhos.html>. Acesso em: jun.2014. 
SALES, L.F.P (2010). Ocupações em Áreas de Risco. Conselho Regional de Engenharia e Agronomia de Santa Catarina. Acesso em: jul.2014. Disponível em: < http://www.crea-sc.org.br/portal/index. php?cmd=artigos-detalhectid $=894 \#$.VACdqWNAd $1 \mathrm{w}>$.

SOUZA, C.J.O (2013); Riscos, geografia e educação. Riscos naturais antrópicos e mistos; Universidade de Coimbra, Departamento de Geografia. Disponível em: < http://www.uc.pt/fluc/depgeo/Publicacoes/ livro_homenagem_FRebelo/127_142>. Acesso em: set.2014.

TUAN, Y (1983). Espaço e lugar, a perspectiva da experiência. Tradução de Lívia de Oliveira, São Paulo. VEYRET, Y(2007). Os riscos: o homem como agressor e vítima do meio ambiente. São Paulo: Contexto.

ZANIRATO, S. et.al.(2008) Sentido do Risco: Interpretações teóricas. Universidade de Barcelona, Revista Bibliográfica de Geografia e Ciências Sociais. Vol. XIII. 